\title{
ASSESSMENT OF ENAMEL RE-MINERALIZATION OF DECIDUOUS TEETH AFTER TREATMENT WITH CURCUMA LONGA LINN. AND CASEIN PHOSPHOPEPTIDE- AMORPHOUS CALCIUM PHOSPHATE FLUORIDE
}

\author{
Muhammad Chair Effendi' ${ }^{1}$, Dyah N. Palupi Pratamawari' ${ }^{2}$ Lidya A. Wulandari', Mutiara Fauzia Nurmawlidina' \\ 'Department of Pediatric Dentistry, Universitas Brawijaya, Malang, Indonesia \\ 2Department of Community and Preventive Dentistry, Universitas Brawijaya, Malang, Indonesia
}

\begin{abstract}
INTRODUCTION: Curcuma longa Linn. (CLL) has high calcium and phosphate concentrations, resulting in increasing re-mineralization of enamel.

OвJECTIVEs: This study was to determine the difference between CLL and casein phosphopeptide-amorphous calcium phosphate fluoride (CPP-ACPF) in the growth of enamel re-mineralization.

MATERIAL AND Methods: CLL 5\% and 10\% were obtained from thick CLL extract and weighed to acquire 50 grams of CLL extract. 2.5 grams of CLL were taken, and 2.5 grams of carboxymethyl cellulose (CMC) and $45 \mathrm{ml}$ of distilled water were added, giving CLL 5\% gel. For CLL 10\% gel, 5 grams of CLL, 2.5 grams of CMC, and $42.5 \mathrm{ml}$ of distilled water were mixed. De-mineralization solution consisted of $2.2 \mathrm{mM} / 1 \mathrm{CaCl}_{2}, 2.2 \mathrm{mM} / \mathrm{KH}_{2} \mathrm{PO}_{4}$, and $50 \mathrm{mM}$ acetate buffer, with $\mathrm{pH}$ of 4.06 . Samples of 24 extracted primary maxillary central incisors were divided into four groups: 1. Negative control group (C-); 2. Positive control (C+) with CPP-ACPF 5\% cohort; 3. CLL 5\%; and 4 . CLL $10 \%$ treatment group.

RESULTS: Mean enamel micro-hardness in CLL 10\% group after re-mineralization at tenth minute time-point $(449.28 \mathrm{HV})$ was higher than that in CPP-ACPF $5 \%$ group (403.41 HV), which was significantly different. Strongest correlation coefficient was observed in CLL 10\% group ( $r=0.820$, very strong), with highest R2 value of $67.2 \%$.

ConcLusions: CLL 10\% is more effective than CLL 5\%. Moreover, CPP-ACPF 5\% was found efficient in increasing enamel re-mineralization, as a potential agent for re-mineralizing primary teeth enamels.
\end{abstract}

KEY WORDS: hardness, curcuma, enamel, tooth re-mineralization.

J Stoma 2022; 75, 1: 19-24

DOI: https://doi.org/10.5114/jos.2021.112039

\section{INTRODUCTION}

In Indonesia, $73.4 \%$ of children between 10 -years and 14-years experience cavities, therefore dental caries remains a problem in this age group [1]. In school-age children, caries rate is show as high as $60-90 \%$, and in adults, it reach- es nearly $100 \%$, causing pain and discomfort [2]. Efforts to prevent the occurrence of caries is to prevent the release of minerals in teeth and their de-mineralization, by improving the process of re-mineralization. A material widely used in dental practice to inhibit enamel de-mineralization is casein phosphopeptide-amorphous calcium

\section{JOURNAL OF STOMATOLOGY CZASOPISMO STOMATOLOGICZNE

AdDress FOR CORRESPONDENCE: Dr. Muhammad Chair Effendi, DDS, MSc, $\mathrm{PhD}$, Ped Dent, Department of Pediatric Dentistry, Universitas Brawijaya, Malang, Indonesia, e-mail: chair.fk@ub.ac.id

ReCEIVED: 18.05.2021 • ACCEPTED: 02.08.2021 • PUBLISHED: 20.12.2021 
phosphate (CPP-ACP). It has a significant contribution to reduce the development of carious lesions on the enamel, and has a significant additive effect that slows de-mineralization process and promotes prebiosis [3-5]. In addition to CPP-ACP, there is casein phosphopeptide-amorphous calcium phosphate fluoride (CPP-ACPF), which aims to improve the process of re-mineralization and to increase tooth resistance to acid, by forming mineral deposits of calcium and phosphate ions with fluorine [6]. Re-mineralization in teeth requires calcium, phosphate, and fluoride [7]. Phosphate is a particle that contains phosphorus, which is needed in the teeth and bones.

Nowadays, modern science is starting to recognize and understand the extraordinary healing qualities of turmeric (Curcuma longa Linn., CLL), and many studies are currently underway to prove its efficacy in systemic and dental health [8]. CLL contains calcium, phosphate, and antibacterial properties [9]. Calcium and phosphate in CLL is deposited on a surface layer of micro-porosity, and then enter porosity of primary tooth enamel [10].

\section{OBJECTIVES}

This study was conducted to determine the difference between CLL and CPP-ACPF in increasing enamel remineralization due to previous de-mineralization. Research hypothesis was that CLL and CPP-ACPF would have a different effect on micro-hardness of primary maxillary central incisors with previous enamel de-mineralization.

\section{MATERIAL AND METHODS}

\section{RESEARCH DESIGN AND SAMPLE}

This study was entirely a laboratory experiment, using a pre-test/post-test control groups design. The samples used were primary maxillary central incisors, which have been extracted due to persistence, and included caries-free teeth, with no fracture, no restoration, and no anomaly. To determine the sample size, Federer formula, i.e., $(\mathrm{t}-1)(\mathrm{n}-1) \geq 15$, was applied [11]. There were 4 study groups, with 6 samples in each group, consisting of untreated negative control group, positive control group with CPP-ACPF 5\% (GC Tooth Mouse), treatment group 1 with CLL 5\% gel, and treatment group 2 with CLL $10 \%$ gel. The total sample group were 24 primary maxillary central incisors.

\section{MAKING THE EXTRACT AND GEL OF CURCUMA LONGA LINN.}

150 grams of CLL powder was obtained by washing and peeling CCL skin, and then placing it in oven for 2 hours at $60^{\circ} \mathrm{C}$. After that, it was milled in a blender and sieved with a 200 -mesh sieve to obtain a fine
CLL powder. CLL was dissolved in 1.2 liters of ethanol $96 \%$, and an extraction was processed by maceration using ethanol $96 \%$. The acquired extract was stored for 48 hours, then stirred using a stirrer, and was concentrated using a rotary evaporator at $50^{\circ} \mathrm{C}$ for 1 hour, until a thick extract was obtained; it was weighed to get 50 grams of CLL extract. From the thick CLL extract, 2.5 grams (5\% of 50 grams) were taken, with 2.5 grams (5\% of 50 grams) of carboxymethyl cellulose (CMC) and $45 \mathrm{ml}$ of distilled water added to obtain $5 \%$ CLL gel. In order to acquire $10 \%$ CLL gel, 5 grams of thick CLL extract ( $10 \%$ of 50 grams) was required and combined with 2.5 grams of CMC ( $5 \%$ of 50 grams) and $42.5 \mathrm{ml}$ of distilled water. The addition of CMC and distilled water to the thick CLL extract transformed the mixture into CLL gel.

\section{ENAMEL HARDNESS TEST}

Twenty-four primary maxillary central incisors of buccal surface were implanted in acrylic resin. Previously, the roots were cut using a low speed micromotor (Strong 207B; Micro Motor, South Korea) with a carborundum disc, until the crown was left (Figure 1). The buccal was planted into a $1 \mathrm{~cm}$ diameter pipe using acrylic resin. The surface of a sample was cleaned for 3-4 minutes with a brush to get a surface clean from debris. Furthermore, the 24 teeth were immersed in a de-mineralization solution of $2.2 \mathrm{mM} / \mathrm{CaCl}_{2}$, $2.2 \mathrm{mM} / 1 \mathrm{KH}_{2} \mathrm{PO}_{4}$, and $50 \mathrm{mM}$ acetate buffer for 1 hour, with $\mathrm{pH}$ acidity of $4.06[12,13]$. They were washed using a syringe and left for 5 minutes, and then, the enamel micro-hardness after application of de-mineralization solution was measured with a Vickers hardness tester (premium micro-Vickers hardness tester, EW-105 series; UK). Tip of diamond indenter was pressed against the surface of a sample, with a load of $300 \mathrm{~g}$ for 10 seconds. The hardness was measured at three different points in each sample, including upper, middle, and lower areas (area close to the cervical), and mean value was calculated. The sample of primary maxillary central incisors was grouped into 4 groups, using random sampling method, with each group consisting of a negative control group without treatment, positive control CPP-ACPF $5 \%$ group, treatment 1 CLL 5\%, and treatment 2 CLL $10 \%$, using a tip applicator. The four groups' samples were placed in different petri dishes openly and left for 5 and 10 minutes, with their hardness measured at 5-minute and 10-minute time-points, in similar way as the method used for measuring enamel microhardness. The use of de-mineralization material (pretest) before CPP-ACPF and CLLapplication (post-tests) was to determine the increase in enamel micro-hardness, which was reduced due to previous de-mineralization [14]. 


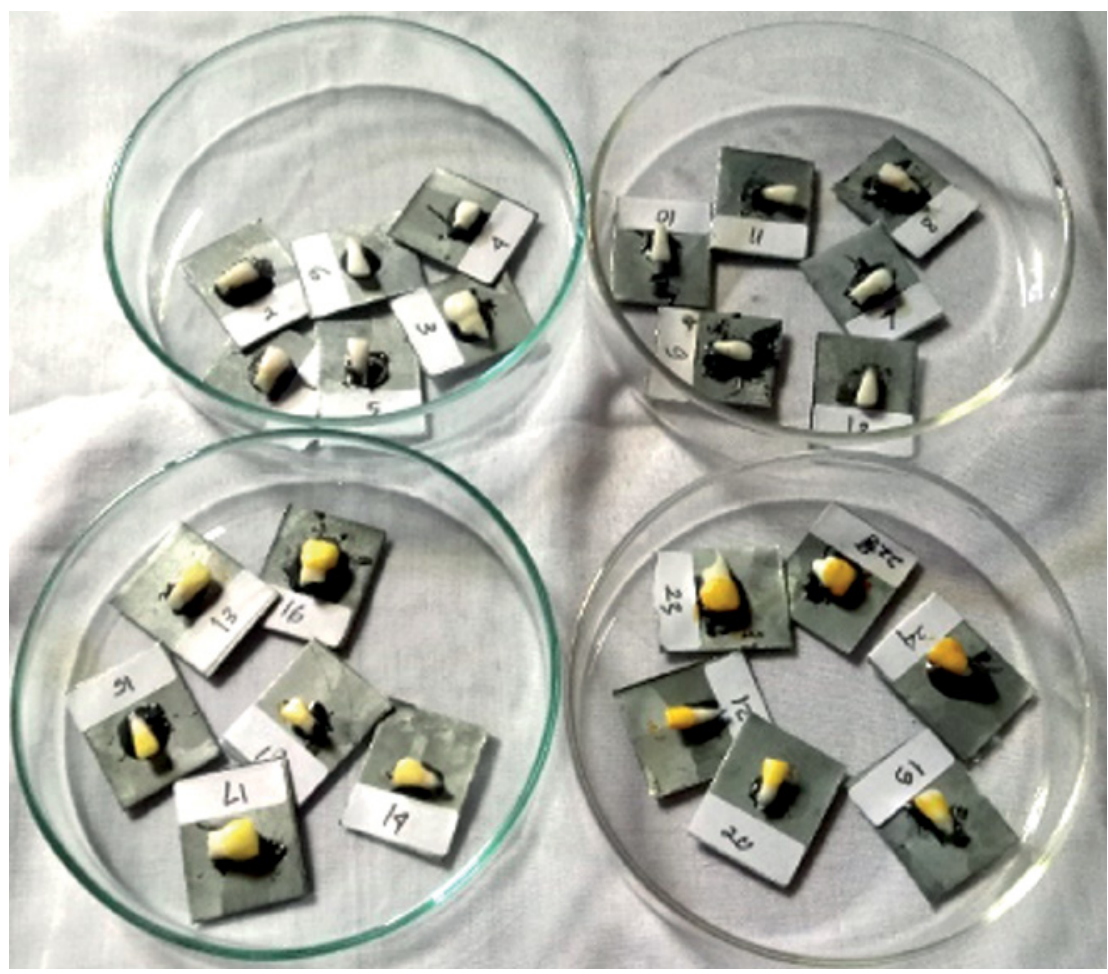

FIGURE 1. Preparation of the specimens for testing (twenty-four primary maxillary central incisors of buccal surface)

\section{STATISTICAL ANALYSIS}

Paired $t$-test was applied to evaluate the differences in enamel micro-hardness before and after re-mineralization treatments in each group. One-way ANOVA test was used to evaluate the differences between the three groups after treatment. $P$-value $<0.05$ was considered statistically significant. If there was a significant difference in ANOVA test, Pearson's correlation test and linear regression were carried out to determine the contribution of length of application time to the increase of re-mineralization.

The study was approved by ethics committee of Faculty of Medicine of the University of Brawijaya, Indonesia (No. 44/EC/KEPK-S1-FKG/02/2017).

\section{RESULTS}

Paired $t$-test illustrated a significant difference in enamel micro-hardness between the de-mineralization groups, with the $\mathrm{C}+$ treatment group at 5-minute timepoint $(p=0.007)$ and the $C+$ treatment group at $10-\mathrm{min}$ ute time-point $(p=0.002)$. There was a significant difference at 5-minute time-point $(p=0.001)$ and 10 -minute time-point $(p=0.000)$ measurements between the de-mineralization groups and the CLL 5\% treatment group. Moreover, the CLL 10\% treatment group presented a significant differences at 5-minute time-point $(p=0.000)$ and 10 -minute time-point $(p=0.000)$ measurements compared to those of the de-mineralization groups. However, re-mineralization at 5-minute and 10-minute time-points of the C+, CLL 5\%, and $10 \%$ groups were not significantly different.

The mean enamel micro-hardness after 5 minutes in the positive control (C+), CLL 5\%, and CLL $10 \%$ groups were $397.00 \mathrm{HV}, 417.55 \mathrm{HV}$, and $428.18 \mathrm{HV}$, respectively, while in the negative control (C-), it was $246.21 \mathrm{HV}$. At 10-minute time-point, the C+, CLL 5\%, and CLL 10\% groups presented $403.41 \mathrm{HV}, 438.55 \mathrm{HV}$, and $449.28 \mathrm{HV}$, respectively, with the $\mathrm{C}$ - group of $232.56 \mathrm{HV}$. The mean enamel micro-hardness of the C- group decreased from $5^{\text {th }}$ minute to $10^{\text {th }}$ minute. According to one-way ANOVA test, at 5-minute time-point, there was no significant difference between the three treatment groups. However, there was a significant difference ( $p=0.000$ ) between the three treatment groups and the $\mathrm{C}$ - cohort. At 10-minute time-point, there was a significant difference between the C+, CLL 5\%, and CLL $10 \%$ treatment groups, and the $\mathrm{C}-$ cohort $(p=0.000)$. The $10 \%$ CLL treatment group differed significantly from the $\mathrm{C}+(p=0.046)$. Nonetheless, the differences between the C+ and CLL 5\%, and between CLL 5\% and $10 \%$ were not significant (Figure 2).

Pearson's correlation test results (Table 1) showed that there was a significant positive correlation between tested material and re-mineralization time. A positive correlation was observed in CPP-ACPF 5\%, CLL 5\%, and CLL $10 \%$ groups, and the longer they remained on the tooth enamel, the more the re-mineralization effect increased. The highest correlation coefficient occurred 


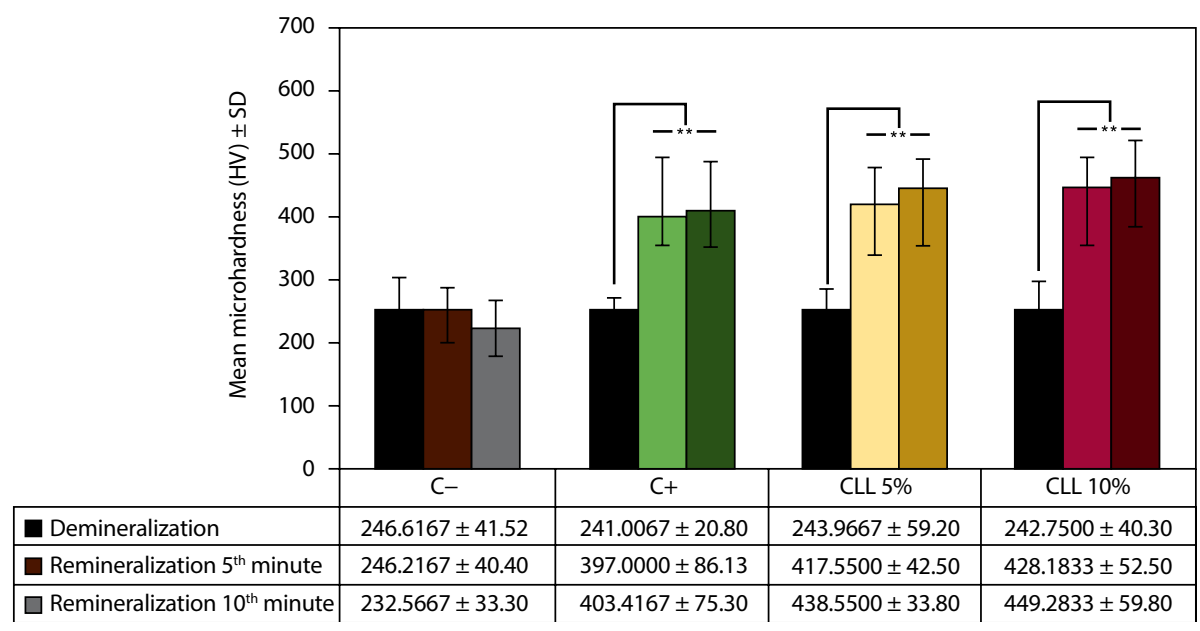

${ }^{*} p<0.05 ;{ }^{* *} p<0.01 ; n s=$ not significant; $S D=$ standard deviation

FIGURE 2. Mean differences in enamel micro-hardness before (de-mineralization) and after treatment (re-mineralization) with CPP-ACPF 5\% (C+), CLL 5\%, and CLL 10\%

TABLE 1. Correlation between tested materials and remineralization

\begin{tabular}{|c|c|c|}
\hline \multirow[t]{2}{*}{ Material } & \multicolumn{2}{|c|}{$\begin{array}{l}\text { Re-mineralization at } 5 \text {-minute } \\
\text { and } 10 \text {-minute time-points }\end{array}$} \\
\hline & $r$ & $p$ \\
\hline CPP-ACPF $5 \%$ & 0.684 (strong) & 0.002 \\
\hline CLL 5\% & 0.809 (very strong) & 0.000 \\
\hline CLL $10 \%$ & 0.820 (very strong) & 0.000 \\
\hline
\end{tabular}

in the CLL $10 \%$ treatment group $(r=0.820, p=0.000)$. Linear regression was applied to determine the contribution of the length of application time to the increase of re-mineralization. The results are presented in Figure 3.

\section{DISCUSSION}

Enamel re-mineralization is very important for teeth to reduce the occurrence of dental caries. Since teeth do not have the ability to re-mineralize, additional re-mineralization agents are needed [15]. Re-mineralization is a process, in which apatite crystals are formed again on enamel, so that enamel's micro-hardness, which declines due to de-mineralization, can improve [14]. Diffusion of calcium and phosphate ions that are good for the re-mineralization process, can occur if there is a low viscosity, allowing re-mineralized gel to penetrate into enamel micro-porosity. Deposition process of calcium and phosphate would then result in closure of enamel micro-porosity, called 'enamel re-mineralization' [11, 16]. Enamel micro-porosity requires a high concentration of calcium and phosphate, which cause a rapid deposition of calcium and phosphate on enamel [17]. One of the reasons for CLL treatment (re-mineralization) is a high mean enamel micro-hardness, since CLL contains
182 grams of high calcium and 268 grams of phosphate $[18,19]$. CPP-ACPF $5 \%$ has a higher re-mineralization effect than CPP-ACP. CPP-ACPF contains free calcium phosphate and active fluoride ion, which helps maintaining saturation and preventing de-mineralization [20]. The mean enamel micro-hardness in the occlusal area is around 359 to $424 \mathrm{VHN}$ (HV). Meanwhile, in the cervical area, the enamel micro-hardness ranges from 227 to $342 \mathrm{VHN}(\mathrm{HV})$. This variation is caused by different factors, such as histological features, chemical composition, specimen preparation (in case of hardness measurements taken), and load errors given in indentation length (IL) [21]. The recommended range of enamel micro-hardness is 227-424 HV [22]. In the current study, all treatment groups showed an increase in the mean enamel micro-hardness, except for the negative control group (C-), where the mean value decreased, since there was no re-mineralization treatment's agent (Figure 2). At $10^{\text {th }}$ minute after the CLL $10 \%$ treatments, the mean micro-hardness was the highest, i.e., $449.38 \mathrm{HV}$, which was significantly different from CPP-ACPF 5\% (403.41 HV), whereas in the CLL 5\% group $(438.55 \mathrm{HV})$, there was no significant difference. At 5-minute time-point, there were no significant differences within the three treatment groups, except for the negative control group (Figure 2). The high mean enamel micro-hardness in the CLL 5\% and CLL $10 \%$ groups were above the recommendations because of a chemical composition of CLL, which has a high calcium and phosphate substances $[17,18,21]$.

In this study, the treatments used in the CPP-ACPF $5 \%$, CLL 5\%, and CLL 10\% groups presented long-term effect; the longer the application on the tooth enamel surface, the better increase of the re-mineralization effect (Table 1). The duration of CLL 10\% application contributed to the $67.2 \%$ of increase in the re-mineralization compared to the C+ 5\% and CLL 5\% treatment 
groups (Figure 3 ). This proves that CLL 10\% has the potential to be a re-mineralization agent for de-mineralized primary teeth enamels. The CLL $10 \%$ can be used on a sub-cellular scale, with high accuracy in reaching cellular targets and obtaining maximum therapeutic effect. CLL can also inhibit cariogenic properties of Streptococcus mutans, proving that CLL essential oils present anti-cariogenic properties [23].

Previous studies have shown that the application of CPP-ACPF has prevented de-mineralization of enamel. In a research of Hendrawan et al., it was observed that application of CPP-ACPF could prevent a significant decrease in micro-hardness of the enamel [24]. Moreover, a research of Zenouz et al. demonstrated that the application of CPP-ACPF could significantly increase micro-hardness of de-mineralized enamel [25]. In line with previous studies, the application of CPP$\mathrm{ACPF}$ in the current study could prevent a decrease in the micro-hardness of the enamel, but the mean value of micro-hardness of the enamel, on which CLL was applied, was higher than in the group of teeth, in which CPP-ACPF used. It shows that CLL is more effective in enhancing re-mineralization of the enamel.

In order to obtain better research results, the initial micro-hardness range of a sample should be reduced, so that it becomes more homogeneous, and therefore, provide more precise results. Moreover, post-test (remineralization) and pre-test (de-mineralization) microhardness measurements should be considered to minimize bias, and to improve accuracy of results [26].

\section{CONCLUSIONS}

The results of the present study show that the CLL $10 \%$ treatment is more effective than the CPP-ACPF $5 \%$ and CLL 5\% in enhancing the enamel re-mineralization of the primary maxillary central incisors. The correlation results demonstrate a positive correlation between the length of time of treatment and the increase in enamel re-mineralization. Moreover, the strongest correlation coefficient and the highest $R^{2}$ of $67.2 \%$ was observed in the CLL $10 \%$ treatment group.

\section{ACKNOWLEDGEMENT}

Thanks to the Head of Mechanical Engineering Laboratory, State University of Malang, the Head of UPT Materia Medica Batu-Malang Laboratory, and all parties who have supported this research.

\section{CONFLICT OF INTEREST}

The authors declare no potential conflicts of interest with respect to the research, authorship, and/or publication of this article.
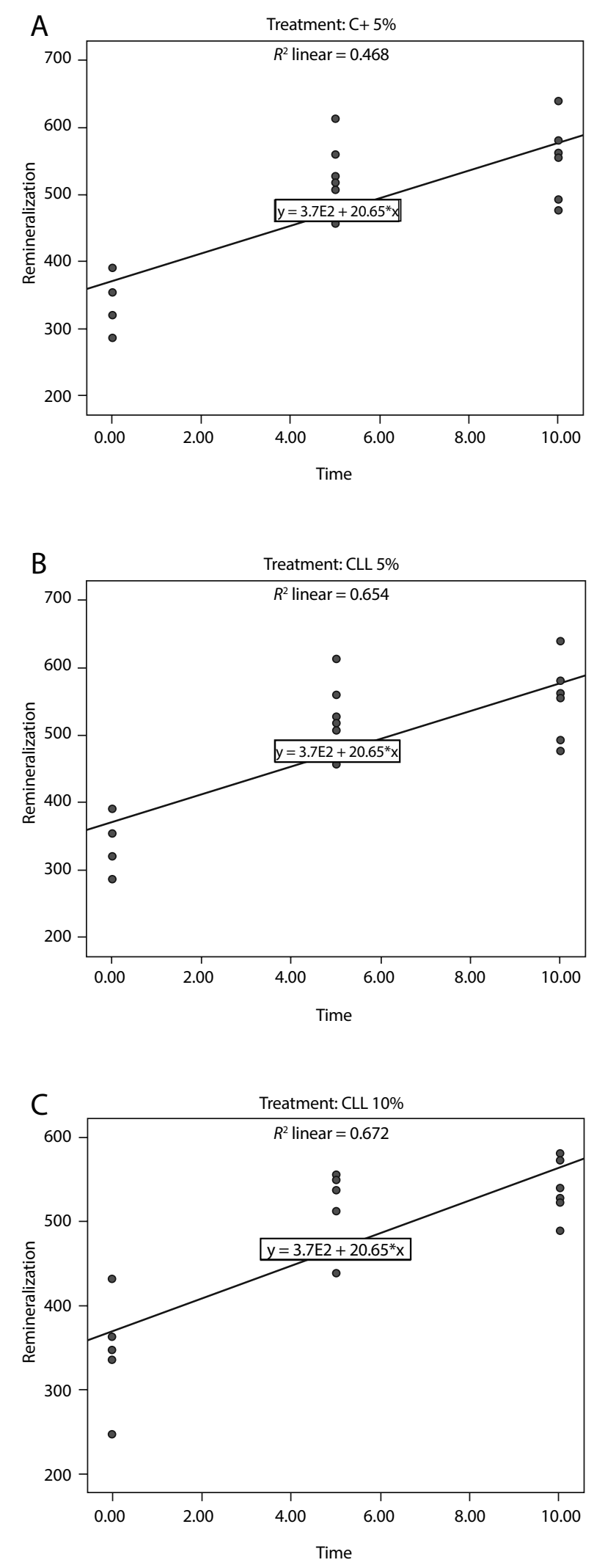

FIGURE 3. A) $R^{2}$ linier C+5\%. B) $R^{2}$ linier CLL 5\%.C) $R^{2}$ linier CLL 10\% 


\section{References}

1. Health Research and Development Office. Main results of basic health research. Ministry of Health RI; 2018.

2. John JR, Daniel B, Panerrselvam D, Rajendran G. Prevalence of dental caries, oral hygiene knowledge, status, and practices among visually impaired individuals in Chennai, Tamil Nadu. Int J Dent 2017; 2017: 9419648. DOI: 10.1155/2017/9419648.

3. Dashper SG, Shen P, Sim CPC, et al. CPP-ACP promotes $\mathrm{SnF}_{2}$ efficacy in a polymicrobial caries model. J Dent Res 2019; 98: 218-224.

4. Alaghemand H, Kamangar SSH, Zarenegad N, Tabari N, Abedi H, Khafri S. In-vitro effect of casein phosphopeptide-amorphous calcium phosphate on enamel susceptibility to staining by tea during bleaching treatment. J Dent (Tehran) 2015; 13: 607-613.

5. Mettu S, Srinivas N, Sampath R, Srinivas N. Effect of casein phosphopeptide-amorphous calcium phosphate (CPP-ACP) on caries-like lesion in terms of time and nano-hardness an in vitro study. J Indian Soc Pedod Prev Dent 2016; 33: 269-273.

6. Wiryani M, Sujatmiko B, Bikarindrasari R. Effect of duration on applying casein phosphopeptide amorphous calcium phosphate fluoride (CPP-ACPF) as a remineralization agent on enamel hardness. Dent J (Indonesia) 2016; 2: 141-146.

7. Margeas R. Remineralization with a unique delivery system. Inside Dent 2006; 4: 86.

8. Shyamala Naidu S, Suresh A. Effects of turmeric (Curcuma longa) in dentistry. Int J Dev Res 2018; 8: 21828-21831.

9. Asnia M, Ambarwati NSS, Siregar JS. The use of turmeric (Curcuma domestica Val.) as a skin care. Prosiding SENDI_U 2019: 697-703.

10. Kathleen H, Lunardhi CGJ, Subiyanto A. The ability of bioactive glass (Novamin) and casein peptide amorphous calcium phosphate (CPPACP) to enamel demineralization. Conserv Dent J 2017; 7: 111-119.

11. Charan J, Kantharia ND. How to calculate sample size in animal studies? J Pharmacol Pharmacother 2013; 4: 303-306.

12. Visveswaraiah PM, Prasad D, Johnson S. Chitosan - a novel way to intervene in enamel demineralization - an in vitro study. Int J Curr Microbiol Appl Sci 2014; 3: 617-627.

13. Arnaud TM, de Barros Neto B, Diniz FB. Chitosan effect on dental enamel demineralization: an in vitro evaluation. J Dent 2010; 38 : 848-852.

14. Fejerskov O, Kidd E (ed.). Dental caries: the disease and its clinical management. $2^{\text {nd }}$ ed. Tunbridge Wells, UK: Blackwell Munksgaard Ltd; 2008.

15. Farooq I, Bugshan A. The role of salivary contents and modern technologies in the reminerealization of dental enamel. A narrative review. F1000Res 2020; 9: 367-373.

16. Tenuta LMA, Zamataro CB, Del Bel Cury AA, Tabchoury CPM, Cury JA. Mechanism of fluoride dentifrice effect on enamel demineralization. Caries Res 2009; 43: 278-285

17. Godoy FG, Hicks MJ. Maintaining the integrity of enamel surface J Am Dent Assoc 2008; 139: 25S-34S.

18. Farrel KT. Spices, Condiment and Seasoning. $2^{\text {nd }}$ ed. New York: A. Van Nostrand Reinhold Company; 1998.

19. Kumar A, Singh AK, Kaushik MS, et al. Interaction of turmeric (Curcuma domestica Val.) with beneficial microbes: a review. 3 Biotech 2017; 7: 357.

20. Berkathullah M, Farook MS, Mahmoud O. The effectiveness of remineralizing agents on dentinal permeability. BioMed Res Int 2018; 2018: 4072815. DOI: 10.1155/2018/4072815.

21. Armencia AO, Gradinaru I, Lese A, Balcos C, Hurjui L, Feier R. Factors that influence the tribological behavior of hard dental structures. Rom J Med Dent Educ 2020; 9: 67-71.

22. Gutierrez-Salazar MD, Reyes-Gasga J. Microhardness and chemical composition of human tooth. Mat Res 2003; 6: 367-373.

23. Lee KH, Kim BS, Keum KS, et al. Essential oil of curcuma longa inhibits streptococcus mutans biofilm formation. J Food Sci 2011; 76: $226-230$.
24. Hendrawan PL, Siregar E, Krisnawati. Efficacy of various topical agents to prevent enamel demineralization. Dent J 2011; 44: 141-144.

25. Zenouz GA, Ezoji F, Enderami SA, Khafri S. Effect of fluoride, casein phosphopeptide-amorphous calcium phosphate and casein phosphopeptide-amorphous calcium phosphate fluoride on enamel surface microhardness after microabrasion: an in vitro study. J Dent (Tehran) 2015; 12: 705-711.

26. Effendi MC, Fitriani D, Nurmawlidina MF. The effect difference of chitosan nanoparticles, chitosan microparticles, and casein phosphopeptide-amorphous calcium phosphate in reducing enamel demineralization. Sci Dent J 2020; 4: 84-87. 